\title{
High brilliance uranium beams for the GSI FAIR
}

\author{
W. Barth, ${ }^{1,2, *}$ A. Adonin, ${ }^{2}$ Ch. E. Düllmann, ${ }^{1,2,3}$ M. Heilmann, ${ }^{2}$ R. Hollinger, ${ }^{2}$ E. Jäger, ${ }^{2}$ \\ O. Kester, ${ }^{2}$ J. Khuyagbaatar, ${ }^{1,2}$ J. Krier, ${ }^{2}$ E. Plechov, ${ }^{2}$ P. Scharrer, ${ }^{1,2,3}$ W. Vinzenz, ${ }^{2}$ \\ H. Vormann, ${ }^{2}$ A. Yakushev, ${ }^{1,2}$ and S. Yaramyshev ${ }^{2}$ \\ ${ }^{1}$ Helmholtz Institute Mainz, 55099 Mainz, Germany \\ ${ }^{2}$ GSI Helmholtzzentrum für Schwerionenforschung, 64291 Darmstadt, Germany \\ ${ }^{3}$ Johannes Gutenberg-Universität Mainz, 55099 Mainz, Germany
}

(Received 2 December 2016; published 15 May 2017)

\begin{abstract}
The 40 years old GSI-UNILAC (Universal Linear Accelerator) as well as the heavy ion synchrotron SIS18 will serve as a high current heavy ion injector for the new FAIR (Facility for Antiproton and Ion Research) synchrotron SIS100. In the context of an advanced machine investigation program in combination with the ongoing UNILAC upgrade program, a new uranium beam intensity record $\left(11.5 \mathrm{emA}, \mathrm{U}^{29+}\right)$ at very high beam brilliance was achieved recently in a machine experiment campaign. This is an important step paving the way to fulfill the FAIR heavy ion high intensity beam requirements. Results of high current uranium beam measurements applying a newly developed pulsed hydrogen gas stripper (at $1.4 \mathrm{MeV} / \mathrm{u}$ ) will be presented in detail.
\end{abstract}

DOI: 10.1103/PhysRevAccelBeams.20.050101

\section{INTRODUCTION}

High current uranium beam machine experiments at the GSI-High Current Injector (HSI) and the gas stripper section were conducted in October 2015 and July 2016, while at this time, due to work on the rf-amplifier system of the UNILAC post stripper (Alvarez), only three of the five Alvarez tanks were available. The achievable high current beam brilliance at injection into the heavy ion synchrotron SIS18 is currently estimated only by using front-to-end high current measurements with a proton beam performed in 2014 [1].

For uranium measurements at UNILAC, a novel multihole extraction system for extracting a high brilliant ion beam from the VARIS ion source [2] was used. Moreover, the HSI radio frequency quadrupole (RFQ) was operated at nominal rf voltage (for uranium operation) by applying a dedicated conditioning and development program. These measures facilitated the extensive beam optimizing program and thus the success of this measurement campaign. The already used pulsed hydrogen stripping target [3] has been further optimized to enable for increased target densities [4], as well as to determine the maximum achievable average charge state. It was found that the average charge state can be increased by approximately three charge units (compared to the conventionally used nitrogen gas jet). The high current measurements were

\footnotetext{
w.barth@gsi.de
}

Published by the American Physical Society under the terms of the Creative Commons Attribution 4.0 International license. Further distribution of this work must maintain attribution to the author(s) and the published article's title, journal citation, and DOI. therefore carried out in charge state $29+$, but the same particle yield is also achievable at lower charge states (e.g., 28+). The maximum beam brilliance before the Alvarez-DTL has been measured.

In routine accelerator operation such peak values can be achieved only through a long-term and sustainable machine development program. Supplemented by extensive beam simulations [5] that were carried out recently for injection of a high-intensity uranium beam (from UNILAC) into the SIS18, the uranium beam intensity, achievable from the FAIR injector chain, has been estimated.

\section{FRONT-TO-END HIGH CURRENT PROTON BEAM MEASUREMENT}

One of the crucial quantities at a fixed beam intensity to characterize the high current capability of a synchrotron injector is the horizontal beam emittance. The high current $(2 \mathrm{~mA})$ proton beam emittance growth inside the Alvarez was measured to be $17 \%$ (rms) [1] (Fig. 1). Considering the overall Alvarez-beam transmission of $90 \%$, the loss of beam brilliance inside the Alvarez is $23 \%$. However, due to a vertical bottleneck in the transfer line to the SIS18 an additional loss of $15 \%$ was measured. The transversal emittance remains the same until injection into the synchrotron. The overall horizontal proton beam brilliance is diminished by $25 \%$ under high current conditions.

\section{U-BEAM OPTIMIZATION AT HSI}

The $\mathrm{U}^{4+}$-beam current and brilliance was improved by applying a multiaperture extraction system [6] at the VARIS ion source [2]. VARIS is a new generation of vacuum arctype ion source. For the uranium beam optimization the ion 


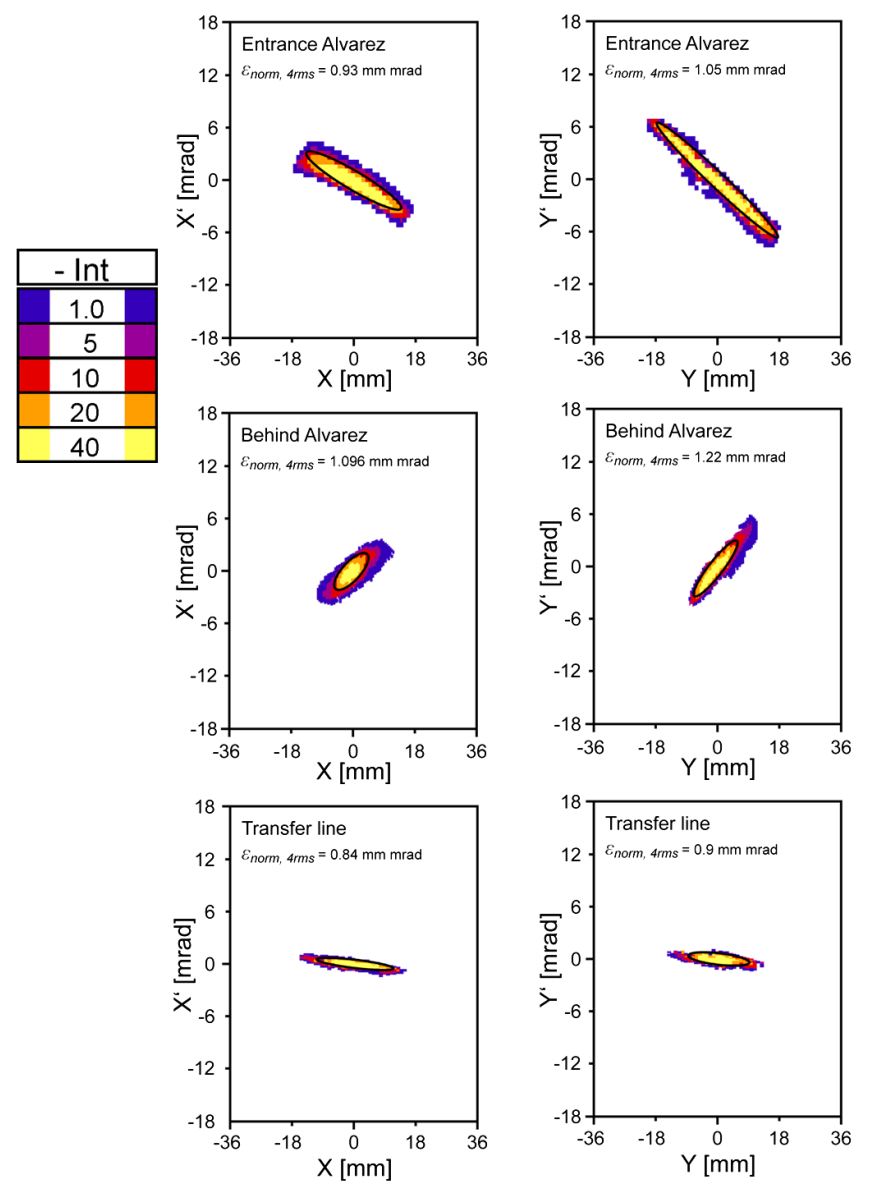

FIG. 1. High- current ( $2 \mathrm{~mA})$ proton beam emittance measurements at GSI-UNILAC and transfer line to the SIS18 [1] using a standard slit-grid measurement device.

source has been operated in $1 \mathrm{~Hz}$ mode. The cathode flange has a revolver system and is equipped with 17 cathodes. The typical lifetime of one uranium cathode is about 8 hours, while about $9.6 \mathrm{~g} /$ day of uranium material is used. For FAIR the ion source has to operate in $3 \mathrm{~Hz}$ mode (maximum), the usage rate increases accordingly. Many other heavy ion species, as $\mathrm{Sn}, \mathrm{Sm}, \mathrm{Ta}, \mathrm{Xe}, \mathrm{Au}, \mathrm{Bi}, \mathrm{Pb}$ has to be delivered in the future, high current capabilities must be investigated fulfilling the strong FAIR requirements.

By optimization of the low energy beam transport and improved RFQ matching an RFQ transmission of $75 \%$ (11.30 emA) was achieved. After rf optimization by adjusting the plunger positions at the HSI RFQ tank and extensive $\mathrm{rf}$ conditioning the forwarded $\mathrm{rf}$ power was reduced to $600 \mathrm{~kW}$, yielding for reliable high current uranium beam operation. Optimizing the Medium Energy Beam Transport between RFQ and IH DTL by increasing the transverse and longitudinal focusing the previously disturbing beam losses could be minimized significantly, resulting in a stable high current operation. After improved beam matching to the gas stripper by adapting the quadrupole channel a beam transmission of $90 \%$ in this section could be achieved. For the first time an
$\mathrm{U}^{4+}$ beam current of $7.6 \mathrm{emA}$ was available for heavy ion stripping. After upgrade of the stripper gas cell an optimal $\mathrm{H}_{2}$ target thickness of $\approx 14 \mu \mathrm{g} / \mathrm{cm}^{2}$ (for stripping into charge state 29+) was available. The charge separation procedure under high current conditions was reoptimized, resulting in an increased absolute stripping efficiency of about $21 \%$.

\section{HIGH CURRENT U-STRIPPING AT A PULSED $\mathrm{H}_{2}$-GAS CELL}

Characterizing the stripping performance, the particlestripping efficiency into the desired charge state is a key indicator. A sufficient charge state resolution is required to enable highest intensities in the desired charge state. As shown in Fig. 2 (with the $\mathrm{H}_{2}$ gas stripper cell) the stripping efficiency (into $28+$ ) could be improved. Applying (instead of a $\mathrm{N}_{2}$ target) a high density $\mathrm{H}_{2}$ target with a stripper back pressure of $7.5 \mathrm{MPa}$ (for charge state $28+$ ) or $12.0 \mathrm{MPa}$ (for charge state $29+$ ) the yield is $65 \%$ higher, the maximum average charge distribution shifts by three charge units. The lead time $(250 \mu \mathrm{s})$ for the pulsed gas injection is set to maximize the gas pressure for the beam pulse transit. This gas pressure (as well as the target density) does not change when increasing the total opening time of the valve further. It could be assumed that the drain-off time of the pulsed gas target does not change when the beam pulse length and, thereby, the valve-opening time is increased. At least the estimated drain-off time is still significantly lower than the minimum time between two beam pulses [7].

With a pulse particle current of $0.397 \mathrm{~mA}$, a new intensity record at $1.4 \mathrm{MeV} / \mathrm{u}$ was achieved. For the equilibrium charge state $(29+)$ the transversal beam emittance (Fig. 3) was measured at an electrical beam pulse

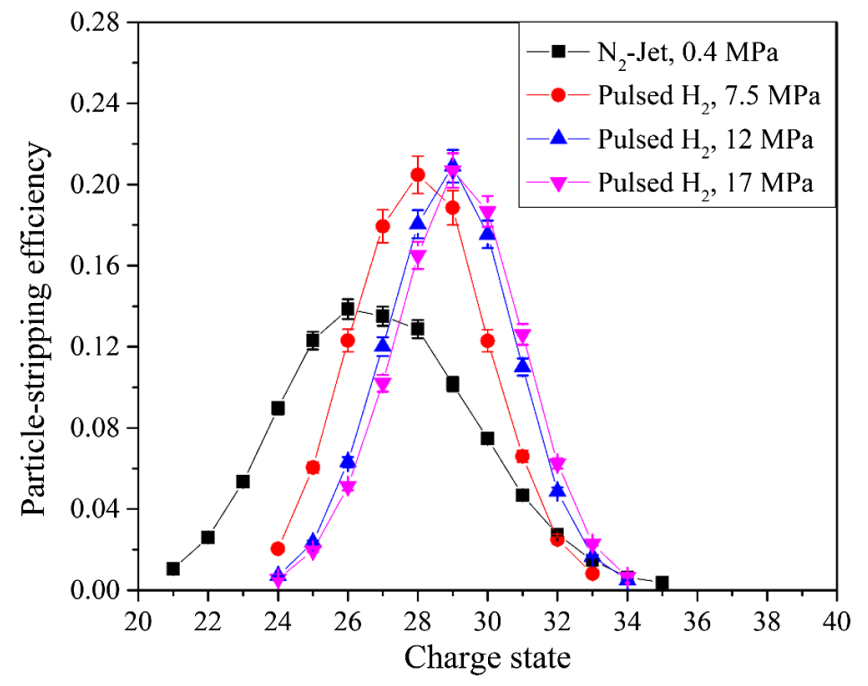

FIG. 2. Charge distribution after stripping of uranium projectiles in a $\mathrm{H}_{2}$ gas target for different target thickness (maximum average charge distribution is depicted in pink color); uranium beam on a $\mathrm{N}_{2}$ target is shown as well. 


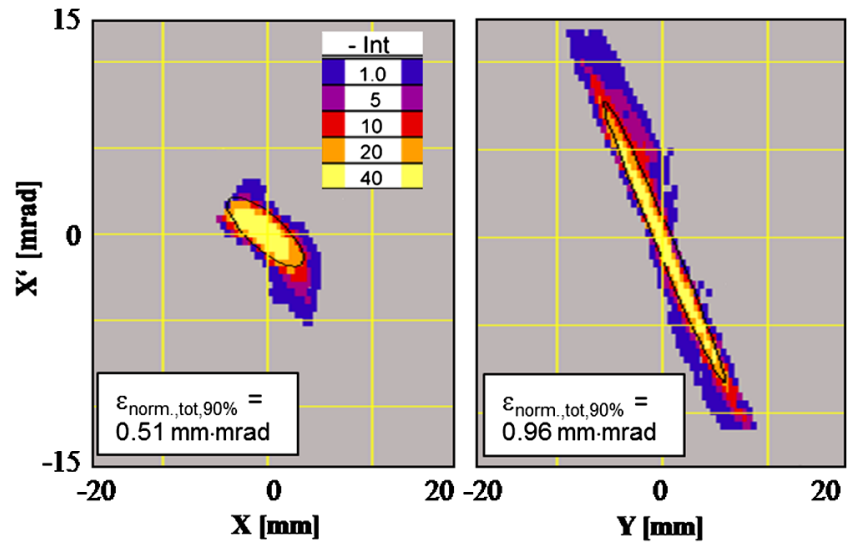

FIG. 3. Measured horizontal and vertical high current (11.5 emA) $\mathrm{U}^{29+}$-beam emittance (at $1.4 \mathrm{MeV} / \mathrm{u}$ ).

intensity of $11.5 \mathrm{emA}$. The main beam parameters achieved with $\mathrm{H}_{2}$ and $\mathrm{N}_{2}$ stripping targets are summarized in Table I.

\section{BEAM BRILLIANCE ANALYSIS}

For a wide range of different current densities and for the $\mathrm{H}_{2}$ as well as for the $\mathrm{N}_{2}$ target the fractional horizontal phase space distributions differ slightly in the peripheral region. The vertical beam emittance for uranium beam on a $\mathrm{H}_{2}$ target (11.5 emA, $\mathrm{U}^{29+}$ ) is significantly increased, while the horizontal emittance is decreased at higher beam current. For the high current beam dynamics layout of the gas stripper section, an enlarged vertical beam envelope in the interaction zone is foreseen, resulting also in an enhanced beam emittance growth due to strong particle straggling. Regarding high space charge power at higher ion beam current, the horizontal phase space distribution has to be reduced as well. Thus horizontal beam brilliance (as shown in Fig. 4 for $\mathrm{U}^{28+}$ ) at $1.4 \mathrm{MeV} / \mathrm{u}$ simply scales with the pulse current. A reduction of the target density along the beam path due to the heat load was not observed. For applications with longer beam pulses ( $\gg 100 \mu \mathrm{s})$ and/or higher repetition frequency further investigations measuring the beam energy loss during have to be conducted.

For the determination of the $\mathrm{U}^{28+}$-beam brilliance at 11.4 MeV/u, achievable at SIS18 injection, the front-toend high current $(2 \mathrm{~mA})$ proton beam measurements were used. Basically the UNILAC parameters scale with the mass-to-charge ratio $\mathrm{m} / \mathrm{q}$ :

$$
\frac{m}{q}(\mathrm{scal})=\frac{m / q\left(U^{28+}\right)}{m / q\left(p^{+}\right)}=\frac{8.5}{1} .
$$

Proton beam transmission $T M_{\text {fin }}$ until SIS18 injection at 11.4 $\mathrm{MeV} / \mathrm{u}$ was measured as

$$
T M_{\text {fin }}\left(p^{+}\right)=75 \%,
$$

while the measured proton rms emittance growth $E W_{\text {fin }}\left(p^{+}\right)$due to losses is

$$
E W_{\text {fin }}\left(p^{+}\right)=-3 \% \text {. }
$$

The resulting proton beam brilliance loss $B L\left(p^{+}\right)$could be evaluated for

$$
B L\left(p^{+}\right)=100 \%-\frac{T M_{\mathrm{fin}}\left(p^{+}\right)}{100 \%+E W_{\text {fin }}\left(p^{+}\right)} \cdot 100 \% \approx 23 \% .
$$

Assuming the brilliance loss scales with ion current density, the brilliance loss $B L\left(U^{28+}\right)$ for the measured maximum uranium beam current (for charge state 28+) of $11.1 \mathrm{emA}$ is

$B L\left(U^{28+}\right)=\frac{11.1 \mathrm{emA}}{2 \mathrm{emA} \cdot \frac{m}{q}(\mathrm{scal})} \cdot B L\left(p^{+}\right)=0.65 \cdot 23 \% \approx 15 \%$.

TABLE I. Measured beam parameters.

\begin{tabular}{lccc}
\hline \hline & $\mathrm{N}_{2}$-gas jet [6] & & $\mathrm{H}_{2}$-gas cell (pulsed) \\
\hline Stripper back pressure & $0.4 \mathrm{MPa}$ & $7.5 \mathrm{MPa}$ & $12.0 \mathrm{MPa}$ \\
$\mathrm{U}^{4+}$-current (HSI) & $6.0 \mathrm{emA}$ & $7.6 \mathrm{emA}$ & $7.6 \mathrm{emA}$ \\
Stripping charge state & $28+$ & $28+$ & $29+$ \\
Maximum uranium current & $4.5 \mathrm{emA}$ & $11.1 \mathrm{emA}$ & $11.5 \mathrm{emA}$ \\
Beam pulse length & $100 \mu \mathrm{s}$ & $100 \mu \mathrm{s}$ & $100 \mu \mathrm{s}$ \\
Stripping efficiency & $(12.7 \pm 0.5) \%$ & $(21.0 \pm 0.5) \%$ & $(21.0 \pm 0.5) \%$ \\
Energy loss & $(14 \pm 5) \mathrm{keV} / \mathrm{u}$ & $(35 \pm 5) \mathrm{keV} / \mathrm{u}$ & $(60 \pm 5) \mathrm{keV} / \mathrm{u}$ \\
$\varepsilon_{x}(90 \%$, total) normalized & $0.76 \mathrm{~mm} \mathrm{mrad}$ & $0.51 \mathrm{~mm} \mathrm{mrad}$ & $0.51 \mathrm{~mm} \mathrm{mrad}$ \\
$\varepsilon_{y}(90 \%$, total) normalized & $0.84 \mathrm{~mm} \mathrm{mrad}$ & $0.96 \mathrm{~mm} \mathrm{mrad}$ & $0.96 \mathrm{~mm} \mathrm{mrad}$ \\
Horizontal brilliance $(90 \%)$ & $5.32 \mathrm{~mA} / \mathrm{mm} \mathrm{mrad}$ & $19.70 \mathrm{~mA} / \mathrm{mm} \mathrm{mrad}$ & $20.29 \mathrm{~mA} / \mathrm{mm} \mathrm{mrad}$ \\
FAIR requirement: & & & \\
$\varepsilon_{x}$ (total) normalized & $1 \mathrm{~mm} \mathrm{mrad}$ & & \\
U $28+$ intensity & $15 \mathrm{~mA}$ & & \\
Horizontal beam brilliance & $15 \mathrm{~mA} / \mathrm{mm} \mathrm{mrad}$ & & \\
\hline \hline
\end{tabular}




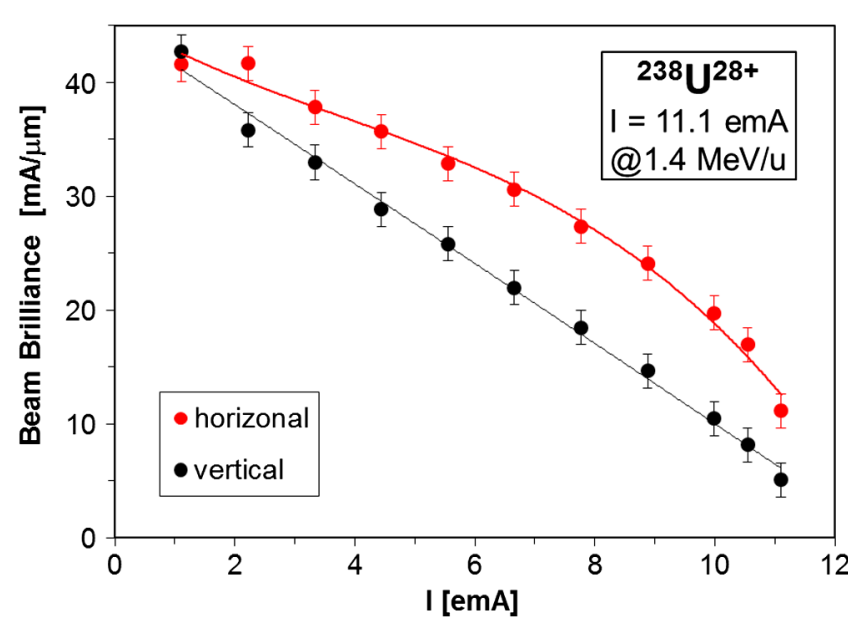

FIG. 4. Horizontal and vertical brilliance (at $1.4 \mathrm{MeV} / \mathrm{u}$ ) for uranium beam on $\mathrm{H}_{2}$-target (maximum $\mathrm{U}^{28+}$ beam pulse current: $11.1 \mathrm{emA})$.

\section{SUMMARY AND OUTLOOK}

Loss-free injection into the SIS18 is an indispensable condition, especially for operation with high intensity intermediate charge heavy ion beams. For this a high pulse current at a low beam emittance is strongly required. By horizontal collimation of the UNILAC beam emittance in the transfer line, the SIS18 space charge limit $\left(\mathrm{I}_{\mathrm{SIS} 18}=187.5 \mathrm{emA}\right)$ could be reached at even lower pulse currents, but accordingly longer injection times. The conducted high current proton beam emittance measurement throughout the UNILAC shows a loss of horizontal beam brilliance of $23 \%$. The high current uranium beam brilliance (measured at $1.4 \mathrm{MeV} / \mathrm{u}$ ) grows until SIS18 injection accordingly. Through horizontal collimation ( $\leq 2 \mathrm{~mm}$ mrad), the number of uranium particles in this phase space area is sufficient to fill the SIS18 up to the space charge limit (see Fig. 5). Within a normalized emittance of $0.31 \mathrm{~mm}$ mrad (total emittance $=2 \mathrm{~mm}$ mrad) an available uranium beam current of $6 \mathrm{emA}$ from the UNILAC corresponds to a normalized beam brilliance of $19.35 \mathrm{~mA} / \mathrm{mm} \mathrm{mrad}$, while 30 turns have to be injected in the SIS18 $[5,8]$.

The UNILAC pulse length has to be increased (by more than a factor of 2) to approximately $140 \mu \mathrm{s}$. For further confirmation, it is evident to perform uranium measurements at full UNILAC energy $(11.4 \mathrm{MeV} / \mathrm{u})$. Beam current and beam emittance, as well as bunch structure and momentum deviation measurements at highest uranium beam intensity have to be conducted to characterize the phase space area to be injected into the SIS18. Finally the high brilliance uranium beam capabilities have to be validated by applying loss free multiturn injection and reaching the space charge limits inside SIS18.

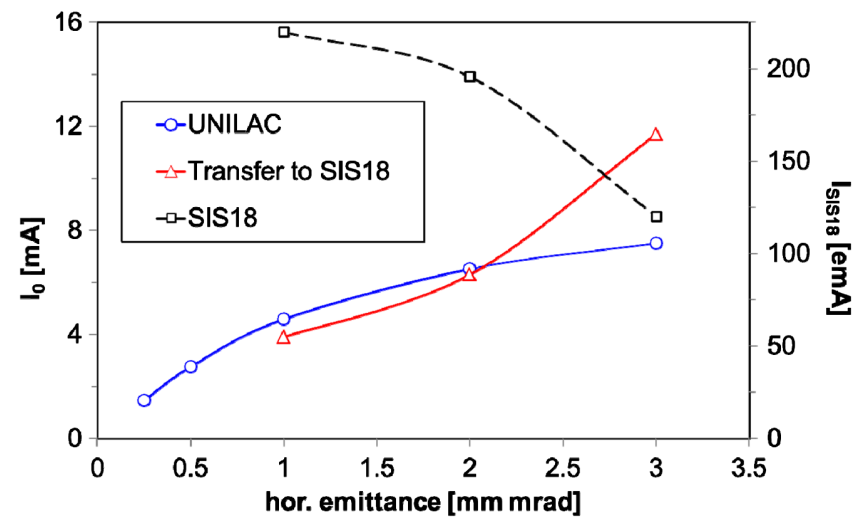

FIG. 5. UNILAC beam current to get in the synchrotron, filling SIS18 up to its space charge limit (red); UNILAC-beam current (measured at $1.4 \mathrm{MeV} / \mathrm{u}$; blue) and overall SIS18 beam current (black) as a function of $\mathrm{U}^{28+}$ horizontal input emittance at SIS18 injection.

\section{ACKNOWLEDGMENTS}

The authors are grateful for the support of the GSI Linac, Ion Sources, Linac RF, Transport \& Installations and Operations department and accelerator operators from other GSI departments.

[1] W. Barth, A. Adonin, S. Appel, P. Gerhard, M. Heilmann, F. Heymach, R. Hollinger, W. Vinzenz, H. Vormann, and S. Yaramyshev, Heavy ion linac as a high current proton beam injector, Phys. Rev. ST Accel. Beams 18, 050102 (2015).

[2] R. Hollinger, and M. Galonska, Status of vacuum arc ion source development for injection of high current uranium ion beams into the GSI accelerator facility, Nucl. Instrum. Methods Phys. Res., Sect. B 239, 227 (2005).

[3] P. Scharrer, E. Jäger, W. Barth, M. Bevcic, C. E. Düllmann, L. Groening, K.-P. Horn, J. Khuyagbaatar, J. Krier, and A. Yakushev, Electron stripping of $\mathrm{Bi}$ ions using a modified 1.4 MeV/u gas stripper with pulsed gas injection, J. Radioanal. Nucl. Chem. 305, 837 (2015).

[4] P. Scharrer et al., An upgrade for the $1.4 \mathrm{MeV} / \mathrm{u}$ gas stripper at the GSI UNILAC, in Proceedings of International Particle Accelerator Conference IPAC2016, Busan, Korea, 2016 (JACoW, Geneva, Switzerland, 2016), pp. 1394-1396.

[5] S. Appel, O. Boine-Frankenheim, and F. Petrov, Injection optimization in a heavy-ion synchrotron using genetic algorithms, Nucl. Instrum. Methods Phys. Res., Sect. A 852, 73 (2017).

[6] W. Barth et al., $U 28^{+}$-intensity record applying a $\mathrm{H}_{2}$-gas stripper cell, Phys. Rev. ST Accel. Beams 18, 040101 (2015).

[7] P. Scharrer et al., Applications of the pulsed gas stripper technique at the GSI UNILAC (unpublished).

[8] S. Appel, SIS18 - Parameter studies on MTI efficiency with space charge and longitudinal aspects, GSI FAIR Injector Review (2013). 